\title{
Age Related Variation in Feminine Handwriting among Population Groups of Delhi, India
}

\author{
Vijit Deepani ${ }^{* 1}$, A.K.Kapoor ${ }^{2}$, and Monika Saini ${ }^{3}$ \\ ${ }^{1}$ UGC-SRF, Department of Anthropology, University of Delhi, Delhi, India \\ ${ }^{2}$ Professor, Department of Anthropology, University of Delhi, Delhi, India \\ ${ }^{3}$ Academic Consultant, School of Social Sciences, IGNOU, Delhi, India
}

${ }^{*}$ Corresponding author: Vijit Deepani, Department of Anthropology, University of Delhi, Delhi-110007, India, Tel: +919818733640, E-mail: ideepani@rediffmail.com

\section{Citation: Deepani Vijit, Kapoor A. K, Saini Monika (2018) Age Related Variation in Feminine Handwriting among Population Groups of Delhi, India. J Forensic Sci Criminol 6(1): 104}

Received Date: June 25, 2018 Accepted Date: July 28, 2018 Published Date: July 31, 2018

\begin{abstract}
Background: Handwriting is a uniquely human trait which progresses and evolves during lifetime and declines with age. The aim of the present paper is to assess variation in handwriting features with age among female writers of select population groups of Delhi, India (for roman script).

Method: A total of 405 handwritten samples were obtained from female $(n=405)$ writers in the age range of 14-60 years. Writers were stratified into three age groups ( $\leq 18$ years, $19-38$ years and $\geq 39$ years) in accordance to population group. Macro- and micro-features of handwriting were extracted from the scanned handwritten samples. These features were subjected to statistical analysis in the objective driven research.

Result: The mean difference among age groups for pen pressure, height of handwriting and handwriting connectivity was statistically significant $(p<0.001)$. Significant difference was also observed among age groups for all micro-features of handwriting selected in the present study, namely, nature of ' $\mathrm{i}$ ' $-\operatorname{dot}(\mathrm{p}<0.001)$, nature of lower loop of ' $\mathrm{g}$ ' $(\mathrm{p}<0.01)$; nature of 'd'- stem $(\mathrm{p}<0.01)$, nature of 'm'-hump $(\mathrm{p}<0.05)$ and ' $\mathrm{r}$ '- shape $(\mathrm{p}<0.001)$.

Conclusion: The present study showed that there was a significant variation in both macro- and micro- features of handwriting with respect to age of the writer. Pen pressure, height of handwriting and handwriting connectivity were prominent macro-features that addressed age related variation in handwriting. In addition, significant variation was observed among age groups for all micro-features of handwriting selected in the present study. The present study has immense forensic significance as it can assist to analyze age of the writer on the basis of handwriting characteristics.
\end{abstract}

Keywords: Demographic Characteristic; Neuro-Muscular Degeneration; Cognitive Performance; Micro Feature; Handwriting Analysis

\section{Introduction}

Handwriting is a complex skill which simultaneously necessitates cognitive and motor - control processing and visual-motor co-ordination of a writer. Handwriting, as a trait, progresses and evolves during lifetime and declines with age owing to neuromuscular degeneration [1-3].

Age of the writer has a significant impact on his/her writing skill. It has been opined that age related changes in handwriting are evidenced as general reduction in pen pressure, irregularity of inter-letter and inter-word spacing, deterioration in the quality and structure of letter forms and variants, inconsistency in the locations of 'initial' strokes and direction and length of terminating strokes, occurrence of erratic movements and above all appearance of fine tremor [1].

Age was observed to significantly predict handwriting parameters, indicating the deterioration in handwriting performance among older persons [4]. Engel-Yeger et al. [2] found that, with age, writing time was longer which lead to writing slow $\neg$ ness. This increased writing time might be linked to degraded sensory-processing abilities, which can lead to ineffective visual-motor perfor $\neg$ mance and deteriorated motor and cognitive performance $[5,6]$.

The aim of the present paper is to assess age related variation in handwriting characteristics (roman script) of female writers of select population groups of Delhi, India. Earlier studies have been carried out with an aim to characterize age either by visual 
observation by assessing features such as letter size, slant, spacing, alignment (with reference to baseline) and number of pen lifts or by automatic feature extraction through computational procedures [7-10]. The present study has made an attempt to employ a set of both quantitative (features extracted at document level using computational algorithm) and qualitative (character shape level features extracted through manual observation) handwriting features to study age differences in handwriting. The study holds immense potential in forensic domain. The study of variation in handwriting features with age has forensic significance because it can assist to analyze age of the writer on the basis of handwriting characteristics.

\section{Materials and Methods}

The methodology is divided into three phases: data collection, feature extraction and statistical analysis. The study was approved by the Institutional Ethics Committee of the Department of Anthropology, University of Delhi, Delhi, India. Subjects were wellinformed about the motive of the study and a prior consent was taken from all the subjects.

\section{Data collection}

Handwritten samples were collected from 405 female subjects, in the age-range of 14-60 years, residing in Delhi and Gurugram (Haryana), India. Delhi is a metropolitan city (also called National Capital Territory of Delhi, India) inhabited by people linked with several ethnic/ caste groups and diverse cultural traditions. Gurugram is a cyber city located in Indian State of Haryana; which is $30 \mathrm{~km}$ away from Delhi. It is included in National Capital Region (NCR) of India. The data, in the present study, was collected from female subjects belonging to four population groups - Khatri (Non-Sikh) ( $n=52)$, Arora (Non-Sikh) ( $n=92)$, Yadav ( $n=161)$ and Hindu Sindhi $(\mathrm{n}=100)$ using random sampling technique.

Khatri and Arora represent two north-Indian mercantile communities primarily following Punjabi linguistic tradition. Sindhi represent mainly an urban community identified by their linguistic tradition (Sindhi), their traditional dress, form of religion (the cult of Varun and the river god, Jhulelal), structure of their name (with the suffix ani) [11]. In present study, Hindu Sindhi have been taken into consideration. The Yadav community, which traces their descent to Lord Krishna of Yadu lineage, has prospered in variety of occupations such as entrepreneurs and businessmen, while adhering to traditional occupation of cattle rearing and dairying [12].

Subjects, in the present study, were stratified into three age groups- $<=18$ years $(n=191), \quad 19-38$ years $(n=138)$ and $>=39(n=76)$ years in accordance to population group (Table 1). The age range was formulated on the basis of statistical percentiles (keeping in mind the concept of graphic maturity). Only right handed female subjects were taken into consideration.

\begin{tabular}{|c|c|r|c|}
\hline \multirow{2}{*}{ Population Group(\%) } & \multicolumn{3}{|c|}{ Age Intervals } \\
\cline { 2 - 4 } & $<=\mathbf{1 8}$ & $\mathbf{1 9 - 3 8}$ & $>=\mathbf{3 9}$ \\
\hline Khatri Non-Sikh & 21.2 & 53.8 & 25.0 \\
\hline Arora Non-Sikh & 23.9 & 50.0 & 26.1 \\
\hline Yadav & 83.9 & 14.9 & 1.2 \\
\hline Hindu Sindhi & 23.0 & 40.0 & 37.0 \\
\hline
\end{tabular}

Table 1: Writer distribution in accordance to demographic characteristics

Subjects were asked to fill the pro-forma which comprised of general information regarding socio-demographic and other cultural attributes. Each subject was also asked to copy the source document (in roman script) in his/her natural handwriting onto a plain sheet with the help of a blue ball pen. The source document comprised of a pangram and a short passage. The short passage had punctuation marks such as comma, inverted comma, exclamation mark and question mark, abbreviations, numerals (0-9) and words of choice. The collected handwritten samples $(\mathrm{N}=405)$ were digitally scanned at 400 dpi (dots per inch) and then used for further analysis. The scanned image was pre-processed to remove noise from the image.

\section{Feature Extraction}

In the present study handwriting features were obtained from scanned images with the help of MATLAB 2016a and Image J 1.6 software.

These features were divided into two classes [13]:

- Macro-features (obtained at the document level (entire handwritten manuscript) or at the paragraph, line, word, and character levels) and;

- Micro-features (obtained at the allograph, or character shape level)

Table 2 provides the list of macro and micro features used and the method used to obtain the handwriting feature. The selected handwriting features can effectively assist in analyzing age related variation in handwriting. Moreover Huber and Headrick [1] have also emphasized that age related changes in handwriting are manifested in pen pressure, inter-letter and inter-word spacing, quality and structure of letter forms and loop features. 


\begin{tabular}{|c|c|c|}
\hline S. No. & Handwriting features & Computing method \\
\hline I & \multicolumn{2}{|r|}{ Macro-features } \\
\hline 1 & Pen pressure & $\begin{array}{l}\text { Gray- level threshold algorithm; computed in Matlab [14] } \\
\text { The higher threshold value indicates light pressure and vice-versa. }\end{array}$ \\
\hline 2 & Slant angle (in degrees) & $\begin{array}{l}\text { Image processing software (Imagej); computed as the inclination of axes of letters in relation to baseline } \\
\text { and averaging it over the entire document. } \\
\text { (Acute angle represents inclined slant, right angle represent vertical slant and obtuse angle represents reclined slant) }\end{array}$ \\
\hline 3 & $\begin{array}{l}\text { Height of Handwriting } \\
\text { (in pixels) }\end{array}$ & $\begin{array}{l}\text { Image processing software (Imagej); Computing distance (in pixels) between the maximum and minimum point } \\
\text { of the vertical dimension of the capital letters and averaging it over the entire document. }\end{array}$ \\
\hline 4 & Handwriting connectivity & $\begin{array}{l}\text { Assessing number of connected components; greater number of connected components specifies printed hand- } \\
\text { writing. }\end{array}$ \\
\hline II & \multicolumn{2}{|r|}{ Micro features } \\
\hline 1 & 'm'- hump shape & \multirow{5}{*}{ Manual observation } \\
\hline 2 & Nature of 'i'- dot & \\
\hline 3 & Nature of 'd'- stem & \\
\hline 4 & Nature of lower loop of ' $\mathrm{g}$ ' & \\
\hline 5 & 'r'-shape & \\
\hline
\end{tabular}

Table 2: List of Handwriting attributes and respective computing method

\section{Statistical Analysis}

Data was entered and statistically analysed using SPSS software (version 23.0). ANOVA (Analysis of Variance; F-test) test was used to compute mean difference among age groups for macro features (continuous variables). In order to assess difference between age groups for micro-features, chi-square $\left(\mathrm{x}^{2}\right)$ test was used.

\section{Results}

Table 3 represent variants or forms of the micro features observed in the feature acquisition process. Figure 1 and 2 depict the types of select macro and micro features obtained in the present research. Table 4 exhibits mean, standard deviation and ANOVA test values of four macro features in accordance to age of female writer (for roman script). It was found that the gray threshold value for age group $\leq 18$ years was significantly lower in comparison to other age groups. The mean difference among age groups for pen pressure was statistically significant $(\mathrm{p}<0.001)$. The mean value of height of handwriting for age group $\geq 39$ years was found to be lowest in comparison to other age-groups. The difference among age intervals for mean value of height of handwriting was also statistically significant $(\mathrm{p}<0.001)$. The mean value of connected component (used as a measure of handwriting connectivity) was found to be highest for age group $\geq 39$ years in comparison to other age-groups. Differences were found to be statistically significant among all age groups for mean value of connected components $(\mathrm{p}<0.001)$.

\begin{tabular}{|c|r|r|r|r|c|}
\hline Micro features & \multicolumn{5}{|c|}{ Classification } \\
\hline 'm'- hump shape & Curved & Angular & - & - & - \\
\hline Nature of ' $\mathrm{i}$ '- dot & Dot & Circle & Slash & Any- other & - \\
\hline Nature of 'd'- stem & Looped & Retraced & Simple-downward & - & - \\
\hline Nature of lower loop of 'g' & Cramped & Broad & Triangular & Open & Without Loop \\
\hline 'r'- shape & Arcade & Parochial & - & - & - \\
\hline
\end{tabular}

(a)

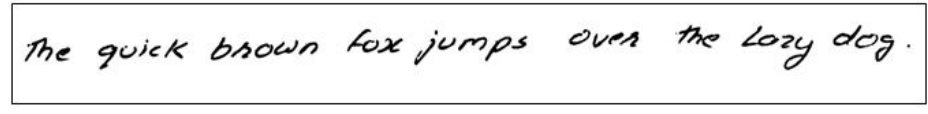

The quick brown fox jumps over the lazy dog.

(b)

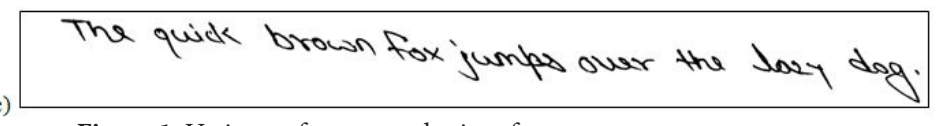

Figure 1: Variants of macro and micro features

Slant: (a) Inclined Slant, (b) Vertical Slant, (c) Reclined Slant

Nature of 'i'dot: (a) Dot, (b) Circle

Shape of ' $r$ ': (a) parochial (c) arcade 
(a) The quick browen fon jumps oner the lazy dog
(b) quick brown for jumps over the lazy dog

The quick brown fox jumps over the lazy dog

Figure 2: Classes of handwriting connectivity

Increase in number connected components with decrease in connectivity between allographs: (a) Cursive: connected components=9; (b) Cursive printed composite: connected components $=27$; (c) Printed: connected components $=45$

\begin{tabular}{|c|c|c|c|c|}
\hline \multirow{2}{*}{ Macro-features } & \multicolumn{3}{|c|}{ Age interval } & \multirow{2}{*}{ F-value } \\
\cline { 2 - 4 } & $\mathbf{1 1 8}$ & $\mathbf{1 9 - 3 8}$ & $\mathbf{3 9}$ & \\
\hline Pen Pressure (Gray threshold value) & $0.713 \pm 0.03$ & $0.714 \pm 0.03$ & $0.731 \pm 0.03$ & $12.01^{* * *}$ \\
\hline Slant angle (in degree) & $85.59 \pm 10.66$ & $84.45 \pm 9.48$ & $85.42 \pm 9.76$ & 0.59 \\
\hline Height of Handwriting (in pixel) & $88.41 \pm 12.71$ & $83.42 \pm 11.72$ & $76.78 \pm 10.34$ & $26.63^{* * *}$ \\
\hline Handwriting connectivity & $20.76 \pm 7.01$ & $21.40 \pm 7.21$ & $27.67 \pm 8.44$ & $25.39^{* * *}$ \\
\hline
\end{tabular}

$* * * p<0.001$

Table 4: Statistical patterns of macro features in accordance to age range (in all the four groups)

Table 5 depicts the percentage distribution of micro features in accordance to age of female writer (for roman script). Chi-square ( $\mathrm{x}^{2}$ ) value has also been calculated to indicate the difference among age groups for micro-features of handwriting. Handwriting samples obtained from writers in age group of $\geq 39$ years exhibited highest percentage $(\sim 80 \%)$ of dot over ' $i$ '- stem. While handwriting samples obtained from writers in age group of $\leq 18$ years exhibited highest percentage $(\sim 73 \%)$ of circle over ' $\mathrm{i}$ - stem. The agegroup $\leq 18$ years was associated with highest percentage $(\sim 57 \%)$ of broad lower loop of ' $\mathrm{g}$ ' followed by age groups of $19-38$ years and $\geq 39$ years respectively. The age- group 19-38 years was associated with highest percentage ( $\sim 80 \%)$ of retraced'd'- stem followed by age groups of $\leq 18$ years and $\geq 39$ years respectively. The age- group $\leq 18$ years exhibited highest percentage ( $\sim 90 \%)$ of curved ' $\mathrm{m}$ '- hump followed by age groups of $\geq 39$ years and 19-38 years respectively. Arcade form of ' $r$ ' was most prevalent for writers in age group $\geq 39$ years ( $\sim 59 \%)$ and parochial form of ' $r$ ' was most prevalent for writers in age group $\leq 18$ years $(\sim 79 \%)$. The difference among age groups for all micro-features was found to be statistically significant.

\begin{tabular}{|c|c|c|c|c|}
\hline \multirow{2}{*}{ Micro-Features } & \multicolumn{3}{|c|}{ Age interval } & \multirow{2}{*}{$\mathbf{x}^{2}$} \\
\hline & $<=18(\%)$ & $19-38(\%)$ & $>=39(\%)$ & \\
\hline \multicolumn{5}{|c|}{ Nature of 'i' - dot } \\
\hline Dot & 27.2 & 50.0 & 80.3 & \multirow{3}{*}{$94.55^{\star * *}$} \\
\hline Circle & 72.8 & 49.3 & 11.8 & \\
\hline Slash & 0.0 & 0.7 & 7.9 & \\
\hline \multicolumn{5}{|c|}{ Nature of lower loop of ' $\mathrm{g}$ ' } \\
\hline Cramped & 25.1 & 31.9 & 51.3 & \multirow{5}{*}{$23.10^{* *}$} \\
\hline Broad & 57.1 & 51.4 & 35.5 & \\
\hline Triangular & 3.1 & 2.9 & 0.0 & \\
\hline Open & 7.3 & 10.1 & 10.5 & \\
\hline Without loop & 7.3 & 3.6 & 2.6 & \\
\hline \multicolumn{5}{|c|}{ Nature of 'd'- stem } \\
\hline Looped & 24.6 & 16.7 & 39.5 & \multirow{3}{*}{$15.94^{* *}$} \\
\hline Retraced & 71.2 & 79.7 & 53.9 & \\
\hline Simple Downward & 4.2 & 3.6 & 6.6 & \\
\hline \multicolumn{5}{|c|}{ Nature of 'm'-hump } \\
\hline Curved & 89.5 & 79.7 & 81.6 & \multirow{2}{*}{$6.66^{*}$} \\
\hline Angular & 10.5 & 20.3 & 18.4 & \\
\hline \multicolumn{5}{|c|}{ 'r'-shape } \\
\hline Arcade & 20.9 & 32.6 & 59.2 & \multirow{2}{*}{$36.55^{* * *}$} \\
\hline Parochial & 79.1 & 67.4 & 40.8 & \\
\hline
\end{tabular}

${ }^{*} \mathrm{p}<0.05 ;{ }^{* *} \mathrm{p}<0.01,{ }^{* * *} \mathrm{p}<0.001$

Table 5: Statistical Patterns of micro features in accordance to age range (in all the four population groups) 


\section{Discussion}

Studies on handwriting kinematics in advanced age reveal multiple findings such as slower speed of handwriting movements, reduced and more uniform pen pressure across strokes, greater stroke variability, increased time of the decelerative phase of movements, and greater reliance on visual feedback compared with younger writers [7,15-21].

The present study was conducted to assess variation in handwriting characteristics with age. It was found that there was a gradual increase in mean gray threshold value (measure of pen pressure) with age. In other words there was a gradual decrease in pen pressure with advancing age. The pen pressure finding is consistent with previous studies [2,7,22-24]. The decline in pen pressure in old age might be linked with degenerative neuro-physical function and ineffective perceptual motor abilities.

There was a gradual decrease in mean value of height of handwriting with advancing age. While, there was a gradual increase in number of connected components (indicative of handwriting connectivity) with age. This suggests that handwriting becomes more printed with advancing age. This might be linked with increase in the number of pen lifts with age and the gradual and progressive loss of control of the writing instrument. Walton [7] found an association between age of the writer and number of pen lifts and stated that younger writers (mean age of 22) lifted the pen on an average 2.7 times within as sentence, whereas the oldest writers (mean age of 75) lifted the pen on average 6.0 times while writing. The increase in number of pen lifts with age might be associated with degenerative neuro-muscular control in the old age.

Most of the handwriting specimen obtained from age group $\geq 39$ years exhibited dot over 'i'-stem, cramped lower loop of ' $\mathrm{g}$ ', retraced 'd'stem, curved ' $m$ '-hump and arcade form of ' $r$ '. There was a significant variation among age-groups for all micro features of handwriting. Moreover it has been shown that individual characteristics of handwriting such as design of letters, letter connections and location of dots are more frequently retained even as time progresses and the writer becomes older [8].

Age related changes in handwriting attributes might be linked with several factors, such as decline in performance speed degeneration in neuromuscular func $\neg$ tion affecting hand strength, speed, and coordination object manipulation; dexterity abili-ties; and impaired perceptual motor skills, all of which are linked with sensory pro-cessing [25-27].

\section{Conclusion}

The present study was conducted to assess variation in handwriting characteristics with age among female writers for roman script. There was a significant variation in both macro- and micro- features of handwriting with respect to age of the writer. Significant differences among age groups were observed for pen pressure, height of handwriting and handwriting connectivity. Age related variation was also found in all micro-features of handwriting selected in the present study.

The study provides crucial insight on the age related variation (an extrinsic parameter) upon handwriting characteristics. The present study has immense significance in forensic research as it can aid to examine and assess age of the writer from handwritten document. Further it can serve as corroborating evidence aiding in authorship determination in questioned document examination. Moreover computer assisted handwriting analysis provide repeatability and objectivity to the result to a certain extent.

\section{Acknowledgment}

VD is grateful towards UGC for providing financial assistance in the form of fellowship. VD is also thankful to Dr. Meenal Dhall, Department of Anthropology, University of Delhi, Delhi-11007, for her valuable suggestions related to statistical analysis. Sincere gratitude is expressed towards subjects for the cooperation in the fieldwork.

\section{References}

1. Huber RA, Headrick AM (1999) Handwriting identification: facts and fundamentals. CRC Press. USA

2. Engel-Yeger B, Hus S, Rosenblum S (2012) Age effects on Sensory-processing Abilities and their Impact on Handwriting. Can J Occup Ther 79: 264-74.

3. Rosenblum S, Engel-Yeger B, Fogel Y (2013) Age-related changes in executive control and their relationships with activity performance in handwriting. Hum Mov Sci 32: 1056-69.

4. Carmeli E, Patish H, Coleman R (2003) The aging hand. J. Gerontol. Series A, Biological Sciences and Medical Sciาences 58: 146-52.

5. Bourdin B, Fayol M (1994) Is written language production more difficult than oral language production? A working memory approach. Int J Psychol 29: 591-620.

6. Lindenberger U, Marsiske M, Baltes PB (2000) Memoriz $i$ ing while walking: Increase in dual-task costs from young adulthood to old age. Psychol Aging 15: 417-36.

7. Walton J (1997) Handwriting changes due to aging and Parkinson’s syndrome. Forensic Sci Int 88: 197-214.

8. Tharmar NM, Sultan MMA, Wong KY (2010) A Study on the age related retention of individual characteristics in handwritings and signatures for application during Forensic Investigation. Malaysian J Forensic Sci 1: 54-9.

9. Van Drempt N, McCluskey A, Lannin NA (2011) Handwriting in healthy people aged 65 years and over Aust Occup Ther J 58: 276-86.

10. Al Maadeed S, Hassaine A (2014) Automatic Prediction of Age, Gender, and Nationality in Offline Handwriting. EURASIP Journal on Image and Video Processing 1: 1-10.

11. Singh KS (1996) People of India: Delhi (Volume XX) Anthropological Survey of India. Manohar Publishers and Distributors, Delhi. 
12. Singh KS (1998) People of India. India’s communities: National series volume VI, Anthropological Survey of India. Oxford University Press. Delhi, India.

13. Srihari SN, Cha SH, Arora H, Lee S (2002) Individuality of handwriting. J Forensic Sci 47: 1-17.

14. Otsu N (1979) A threshold selection method from gray-level histograms. IEEE Trans Syst Man Cybern Syst 9: 62-6.

15. Dixon RA, Kurzman D, Friesen IC (1993) Handwriting performance in younger and older adults: Age, familiarity, and practice effects. Psychol Aging 8: 360-70.

16. Rodriguez-Aranda C (2003) Reduced writing and reading speed and age-related changes in verbal fluency tasks. Clin Neuropsychol 17: $203-15$.

17. Burger DK, McCluskey A (2011) Australian norms for handwriting speed in healthy adults aged 60-99 years. Aust Occup Ther J $58: 355-63$.

18. Rosenblum S, Werner P (2006) Assessing the handwriting process in healthy elderly persons using a computerized system. Aging Clin Exp Psychol 18: 433-9.

19. Slavin MJ, Phillips JG, Bradshaw JL (1996) Visual cues and the handwriting of older adults: a kinematic analysis. Psychol Aging 11: 521-6.

20. Teulings HL, Contreras-Vidal JL, Stelmach GE, Adler CH (2002) Handwriting size adaptation under distorted visual feedback in Parkinson's disease patients, elderly and younger controls. J Neuropsychiatr Neurosurg Psychiatr 72: 315-24.

21. Contreras-Vidal JL, Teulings HL, Stelmach GE, Adler CH (2002) Adaptation to changes in vertical display gain during handwriting in Parkinson's disease patients, elderly and young controls. Parkinsonism Relat Disord 9: 77-84.

22. Caligiuri MP, Kim C, Landy KM (2014) Kinematics of signature writing in healthy aging. J Forensic Sci 59: 1020-4.

23. Holekian F (2014) Handwriting Analysis: The Role of Age and Education. International Journal of Modern Management and Foresight 1: 208-21.

24. Saini M (2018) Forensic Variability of handwriting among Indian Population. Selective and Scientific Books, Delhi.

25. Jiménez-Jiménez FJ, Calleja M, Alonso-Navarro H, Rubio L, Navacerrada F, et al. (2011) Influence of age and gender in motor performance in healthy subjects. J Neurol Sci 302: 72-80.

26. Cole KJ, Rotella DL, Harper JG (1999) Mechanisms for age-related changes of fingertip forces during precision gripping and lifting in adults. J Neurosci 19: $3238-47$.

27. Tseng MH, Chow SMK (2000) Perceptual-motor function of school-age children with slow handwriting speed. Am J Occup Ther 54: 83-8.

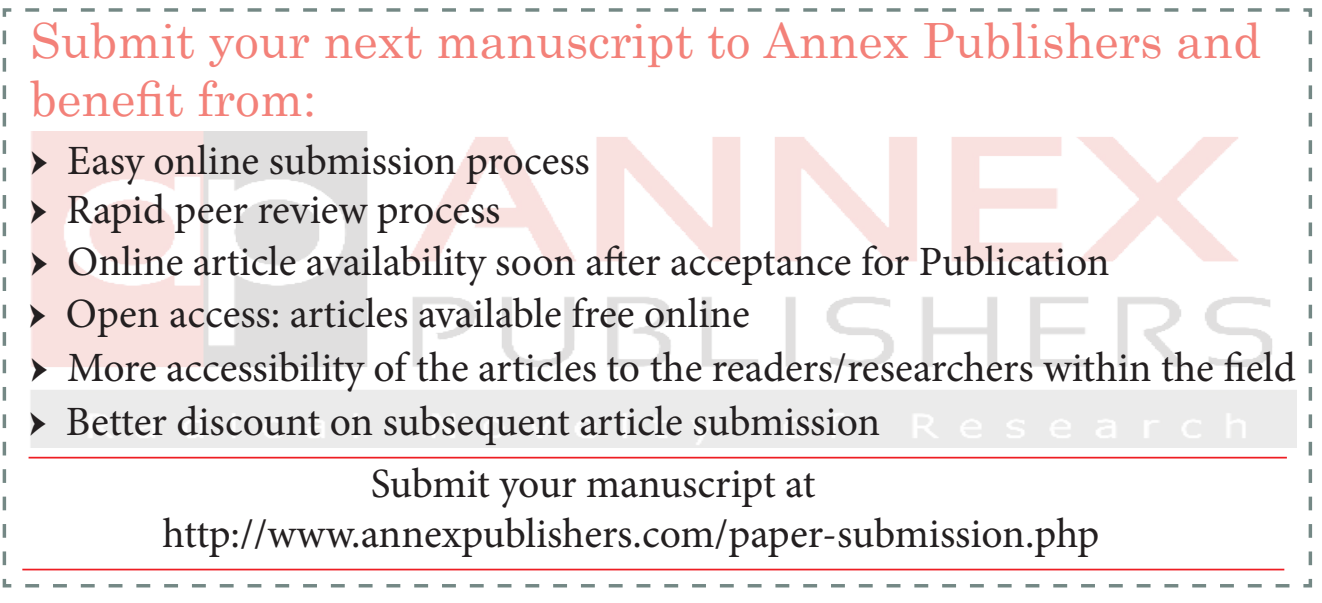

